\title{
Defining Intercultural Education for Social Cohesion in Malaysian Context
}

\author{
Amrita Kaur \\ Universiti Utara Malaysia \\ Malaysia \\ Rosna Awang-Hashim \\ Universiti Utara Malaysia \\ Malaysia \\ Mohammad Noman \\ Universiti Utara Malaysia \\ Malaysia
}

\begin{abstract}
Schools are considered as powerful institutions that are capable of fostering a sense of coherence and common identity to integrate students of different ethnic, social, and cultural origins. Effective implementation of intercultural education at schools can facilitate social integration. However, it is important that the design and implementation of intercultural education be guided by the knowledge and understanding of the issues and patterns of discrimination and complexities within its context. This qualitative study explored perspectives of key stakeholders involved in the education process to define a framework for intercultural education in Malaysian context for successful social cohesion. The findings are discussed in terms of practical application for educators, researchers, and policymakers.
\end{abstract}

KEYWORDS: intercultural education, social cohesion, Malaysia, diversity, school environment

Malaysian Context: Cohesion and Intercultural Education Methodology: Design and Participants

Data Collection

Data Analysis

Findings

Discussion and Conclusion

References

Author Contact

Diversity has become a global phenomenon. As a result of globalisation, internationalisation polices, and political conflicts, demographics are changing rapidly and creating heterogeneous and complex milieus across the world in terms of cultures, religions, languages, perspectives, and ideologies (De Wit, 2011; United Nations, 2013). A vast body of research extends evidence that heterogeneous environments promise innovative solutions, broader perspectives, 
effective cognition, better intellectual growth, and critical abilities (Denson \& Chang, 2009; Terenzini, Cabrera, Colbeck, Bjorklund, \& Parente, 2001; Van Knippenberg, West, Dawson, \& Homan, 2010). Shahran (2014) explains in a psycho-spiritual way that diversity contributes towards the widening spectrum of knowledge that creates alternative views and helps people develop different perspectives, thus helping them generate alternative ways towards solving a problem. However, the outcomes of diversity can be appreciated only when diversity is managed effectively. A theoretical perspective anchored in social identity theory (Tajfel \& Turner, 1979) suggests that, as individuals, we are motivated to divide the world into two groups: an in-group with which we perceive commonalties and an out-group with which we do not have similarities. This psycho-social approach brings forth differences between diverse groups and acts as a barrier towards celebrating and benefitting from diversity. Therefore, failure to understand or inability to manage diversity can pose critical challenges that may lead to conflicts, civil inequality, crime, discriminatory practices, and widening distances between groups, as well as hampering integrity and cohesion in society. A society divided along cultural and ethnic boundaries will create constraints for its social, economic, cultural, and political development and well-being. Therefore, achievement of social cohesion becomes a significantly important issue for every nation.

On June 26, 2015, the American Educational Research Association (AERA) issued an online Statement on the Charleston Shootings and Racism in the United States. The statement highlighted the deteriorating state of race relations in the country, a condition potentially capable of inciting appalling violence. Religion-, race-, or ethnicity-related conflicts have become a common occurrence in the world. In the present times, as diversity expands, the pattern of discourse suggests that mutual tolerance is experiencing diminution, making it a critical global issue. (Cummins, 2015; Fisher, 2013). The AERA statement, while expressing deep concern over this crisis, suggested school education as the most powerful medium to transcend this intense systemic problem across our societies. According to AERA, "education has both a responsibility and an opportunity" as a social institution to educate future citizens about race issues and foster mutual understanding and respect for each other. The statement further calls upon educators, practitioners, policy makers, and scholars to indulge in research initiatives to examine "how school environments may exacerbate race bias and racism" for social harmony (AERA, 2015). Schools are powerful institutions that not only impart literacy, numeracy, and scientific education for core subjects but also play a key role in character building and instilling citizenship among learners.

Ecological system theory (Bronfenbrenner, 1979) proposes that children's development in terms of their identity formation is impacted by various factors that surround them. Schools being situated closest to them are considered as a microsystem where students experience bidirectional relationships with the stakeholders involved in it and, therefore, those stakeholders act as an important agent towards the development of child's identity. The socio-cultural forces experienced within a school environment significantly affect students' social cognition and social identity development and guide their social behavior (Awang- 
Hashim, Kaur, \& Noman, 2015). Rutkowski, Rutkowski, and Engel (2014) articulate that schools, by creating homogeneity between students of different ethnic, social, and cultural origins, are capable of fostering a sense of coherence and common identity for societies.

Therefore, grounding our assumption in social identity theory (Tajfel \& Turner, 1979) and ecological system theory (Bronfenbrenner, 1979), we propose that school and its agents have the potential to exert significant influence over individuals' social identity development. Thus, design and implementation of effective and appropriate interventions guided by these agents at schools can result in desired social behaviours (e.g., social cohesiveness) and favorable identity development of the students at schools.

\section{Malaysian Context: Social Cohesion and Intercultural Education}

A country's social cohesion is central to its continuous and multidimensional development. The discourses surrounding social cohesion have proposed multiple concepts mainly in terms of the social, economic, cultural, and political dimension of cohesion (e.g., Commission of European Communities, 2010; Vergolini, 2011). However, in alignment with the purpose of the present study, we focus on the social and cultural dimension of this construct. A variety of phrases describe this

dimension as a sense of belonging and engagement towards a common enterprise using shared values, interaction, dialogue and consultation between communities, widespread commitment towards tolerance, accommodation, and respect for each other (see Vergolini, 2011).

Official discourse on social cohesion in Malaysian context is mainly established under the label of nation building, of which the main elements have been Malaysian racial diversity and social integration (Malakolunthu \& Rengasamy, 2013; Yaacob, 2011). Malaysia comprises three major ethnic groups-Malays, Chinese, and Indians - with other smaller ethnic groups like Iban, Bidayuh, Melanau, Kelabit, Kedayan, Kadazan, Murut, Dusun, Biasaya, and Bajau. It also includes indigenous people of Sabah and Sarawak, forming a pluralistic society with multiple religions, cultures, languages, and ethnicities (Yaacob, 2011). The nation has always strategized in numerous ways through policies and initiatives to achieve unity, integrity, and social cohesion among its inhabitants. The popular national agendas such as Rukunegara (national principles), Bangsa Malaysia (united Malaysian nation), and Satu Malaysia (one Malaysia) place significant emphasis on the issue of unity and aim at creating oneness in society (Saad, 2012). The principles and philosophy of these agendas, in general, guide Malaysians to recognise and accept diversity and respect cultural and religious differences for peaceful coexistence. Malaysian political culture also indicates that achieving national unity is crucial for the nation to engage as a united and progressive unit in the face of globalisation. This initiative is one of the five major aspirations recently encapsulated in the Malaysian Education Blue Print 2013-2025 for education transformation planning. The document aspires to "an 
education system that gives children shared values and experiences by embracing diversity" (p.8).

Towards this objective, the education system has made consistent efforts in bringing integration for social cohesion by incorporating cultural elements in curricula through civic education (Fakhri, 2012), introducing extracurricular activities like Student Integration for Unity Plan (Montesino, 2011) and the Vision School project (Malakolunthu, Saedah, \& Rengasamy, 2010), and a language policy that oscillates between English and Malay language as a medium of instruction in national schools (Ha, Kho, \& Chng, 2013). However, in the absence of a concrete framework to define and guide the implementation and benchmarking, the success of those outcomes remains elusive in Malaysian discourse on social cohesion through education (Malakolunthu, 2009; Yusof, 2008).

The potential way forward towards the achievement of racial integration through education, as recommended in AERA's statement (2015), is through intercultural education whose design is guided and rooted in the local context. Cummins (2015) also explains that intercultural education is a potential tool for schools to foster values for social cohesion among their students. According to Cummins, intercultural education focuses on "recognizing, respecting, and celebrating diversity within the educational system" (p. 458). It systematically exposes students to a variety of cultures and creates meaningful experiences for them, which, in turn, enhance knowledge of, understanding of, and appreciation for cultural traditions and beliefs of others. However, design and implementation of an intercultural education framework is a sensitive and critical issue and demands serious consideration of specific contexts.

The context that prompts the need for intercultural education varies from one place to another. Borrowed concepts, policies, and practices from one context may not yield similar results in another context. For example, intercultural education in the European context was triggered by rapid migration in the past years. Catarci (2014) compares a number of approaches toward intercultural education across Europe where the approaches in each country vary as they are significantly influenced by the government policies, initiatives, or priority agendas. The United Kingdom emphasizes enhanced academic achievement for minorities and citizens to achieve national cohesion, whereas in France the focus of intercultural education relies on equity for all students with linguistic and cultural assimilation for social cohesion (Allemann-Ghionda, 2008).

In Malaysian context, the need for social cohesion between existing races demands a serious consideration in designing intercultural education. Distinctiveness in multiple cultural and religious practices and beliefs can pose serious challenges for intercultural education; therefore, the design and implementation of intercultural education should be guided by the knowledge and understanding of the issues and pattern of discrimination with particular social groups and the degree of complexities in power relations across cultural groups. Also, the recommendations for intercultural education should be consistent with the country's policy and legal framework (Cummins, 2015). The ultimate goal of 
intercultural education lies in improving race relations; therefore, its practice and recommendation should not contradict the beliefs or practices of cultures involved in it. For example, the structural and cohesion policies for equity agenda in France prohibit religious symbols to be carried to school (Allemann-Ghionda, 2008), which would be unthinkable in Malaysian context. The dimensions for intercultural education should be context-specific and aligned within the local social framework. Therefore, it becomes a pertinent question to explore how intercultural education can be defined and implemented in Malaysian context for effective outcomes for social cohesion. The present qualitative study aims to explore perspectives of key stakeholders in the education process to define a framework for intercultural education in Malaysian context for successful social cohesion.

\section{Methodology: Design and Participants}

This study focused on investigating perspectives of stakeholders involved directly and indirectly in education on the structure of intercultural education for social cohesion in Malaysian context. Therefore, the study adopted a qualitative research design and collected data in two steps.

Table 1. Details of the Participants for In-depth Interviews in the Study

\begin{tabular}{lllll}
\hline Position & ID & Gender & Age & Race \\
\hline School leaders & L1 & Male & 43 & Indian \\
& L2 & Male & 46 & Malay \\
\hline School teachers & T1 & Female & 29 & Indian \\
& T2 & Female & 28 & Malay \\
& T3 & Female & 30 & Malay \\
& T4 & Male & 42 & Indian \\
& T5 & Female & 33 & Chinese \\
\hline Scholars at higher & S1 & Female & 46 & Malay \\
education & S2 & Female & 50 & Malay \\
& S3 & Male & 52 & Chinese \\
& S4 & Male & 45 & Indian \\
\hline Master trainers for diversity & DT1 & Female & 50 & Malay \\
& DT2 & Female & 38 & Malay \\
\hline Parents & P1 & Female & & Malay
\end{tabular}




\begin{tabular}{lllll}
\hline & P2 & Female & 44 & Indian \\
& P3 & Male & 50 & Indian \\
\hline High school students & HS1 & Female & 18 & Chinese \\
& HS2 & Female & 19 & Malay \\
\hline
\end{tabular}

As the first step, given the role and significance of school leaders in determining the structure of intercultural education for social cohesion, the data were collected using a semi-structured survey questionnaire from 94 school leaders (28 females and 66 males) during a two-day-long national seminar. Surveys in qualitative research are considered a rich and valid source of information as they facilitate the participant to respond without being influenced by the researcher (Jansen, 2010; Schaefer \& Dillman, 1998). This step of data collection also guided us in the second round of data collection that involved faceto-face in-depth interviews with open-ended questions from school leaders, school teachers, scholars, diversity trainers, parents, and students. In-depth interviewing is a key method used extensively across the social sciences for data collection. This approach is deemed suitable when the study aims to explore participants' perspective on a particular situation or topic. Open-ended and probing questions used for interviewing help in eliciting relevant information and obtaining rich data (Creswell, 2015). However, Creswell (2015) cautions about careful design of the process and the question to be asked, as well as about selection of the participants for the best outcomes of this approach.

The stakeholders were chosen using purposive sampling techniques aimed at generating suitable representation of members involved directly or indirectly in the education process. The intended selection criterion for the study was to have fair representation of each race for each category. The participants were invited personally to participate in the study and were promised strict confidentiality of their responses. The teachers were chosen on the basis of their race and their teaching experiences through the snowball sampling technique. All teachers involved in the study were teaching in national high schools with student population from three or more races across Malaysia. Table 1 provides the details of the participants for in-depth interviews in the study.

\section{Data Collection}

The data were collected over a period of 10 months. School leaders were accessed during a two-day-long national seminar, and their responses were collected using open-ended questions. Out of 94, two school leaders, who volunteered to participate, were chosen for face-to-face in-depth interviews along with other interviewees in different categories.

For the face-to-face interview, participants were interviewed at a place of their convenience and choice. A separate interview protocol for each category of 
participants was designed. However, the basic approach adopted was the informal conversational interview (Gall, Gall, \& Borg, 2003). The interview sessions involved a brief introduction of the research background and objective of the study followed by the main research open-ended question: i.e., "How do you think Malaysia can strategize, plan, or design intercultural education keeping the local context in consideration?" There were several probing questions used during the interviews to elicit response and maneuver the direction towards the main inquiry, for example, "Do you think that would be appropriate? Will there be any challenges to that idea? How do you think this can be done better?"

The interview sessions for each category varied from 20 minutes to 90 minutes. The data were collected by the researchers involved in the study. For some interviews, more than one researcher was present. All the data were recorded with the participants' consent.

\section{Data Analysis}

The audiotaped transcript from all the interviews and the responses from semi-structured survey questionnaires were transcribed together with the help of a research assistant. The transcript was read and reread to exclude irrelevant and redundant information. The data collected from all the stakeholders involved in the education process directly or indirectly provided multiple perspectives that served the purpose of triangulation. Some of the participants agreed to participate in member check, which helped in increasing the accuracy and validity of the data (Harvey, 2015). In the first round, the data analysis was carried out separately by all the researchers. "Strategies for intercultural education for social cohesion" was considered as a unit of analysis for initial coding (Chenail, 2012). After the initial coding, the three researchers came together to discuss and compare the codes. As the inferences were drawn inductively from the codes, recurring patterns were identified and the codes were then assigned categories. Naming of the categories was agreed through consensus. In the final round, the major categories were arranged systematically under appropriate themes.

\section{Findings}

The following section discusses the main findings using several categories under four main themes. The findings section elaborates on data interpretations drawn from the interviews and semi-structured questionnaires supported by verbatim evidences, with authors' translation in English given in brackets for Malay terms. The findings are summarized into four broad themes; however, within these themes we discuss a variety of approaches and strategies that participants described for designing intercultural education in Malaysian context. 


\section{Awareness of Valuing Multiculturalism}

The findings reveal that bringing awareness of the concept, processes, and outcomes of interculturalism among the stakeholders was a key prerequisite for strategizing intercultural education in Malaysian context. S1, for example, said:

In old times we grew up in a system that used to be race blind...we could not perceive differences amongst us. Gradually the divide became wider and now it is difficult for all to comprehend the efforts and their direction.

It was suggested that it is crucial that everyone involved understand "the need, importance, seriousness and direction" of this discourse in the country (S2). Initiatives taken towards this aim should primarily highlight educational benefits of interculturalism. "The first world countries are exposing their students towards diversity for global competencies and we take our diversity for granted," said L1. According to him, Malaysia should benefit with its naturally occurring diversity. A conscious awareness of existence of multiple cultures and diversity in positive light will facilitate an appropriate handling of discriminatory issues: "When people understand that, yes, there are differences but those differences are good for us, that makes us stronger, people will be more careful of their behaviors" (S3). The teachers felt that civic subjects that encompass elements of multiculturalism "are not enough" in raising appropriate knowledge among students, whch is favorable in conceiving multiculturalism in Malaysian society. As T3 said, "Just knowing about different cultures and customs is not enough; the reason behind knowing them and appreciating them is more important."

Diversity trainers emphasized that training on multiculturalism across various sections of the society can contribute positively towards a better understanding of multiculturalism and its purpose. Training for multiculturalism or diversity is a potential tool in achieving this goal. DT1 remarked, "Tailored training programs for professions especially for educators can help them gain knowledge and skills for handling issues in multi-cultural society." DT2 explained further:

School leaders and teachers lack exposure for interculture education in teacher education as well as professional development. Therefore, the 16 values teachers need to nurture across curriculum but we are not sure how much teachers have understood and embraced those values.

Scholars and principals in general expressed that it has become essential for Malaysia to incorporate intercultural education in teacher education courses and professional development courses. For example, P3 described that "teachers get no formal training or courses to understand the fundamental of diversity and how it can enrich their classes and learning experiences."

\section{Policy Design, Implementation, and Monitoring}


The policies, agendas, or initiatives for intercultural education and related concepts offered for schools or for the society must be rooted in the local context. The policies should be philosophically and theoretically driven. As S3 said, "The policy design process must follow the ground-up approach so that the policies are rooted in real life contexts in Malaysia." It is suggested that a community set-up that connects school practitioners, researchers, and policy makers can facilitate in devising policies that are relevant and have clear design for implementation. "Each year there is a new drive at the national level but schools had no say in them, also we don't know how to promote them at school," L2 said. The focus of discussion needs not only to rely on policy design and implementation but also seek to establish a monitoring process at the national level for a multicultural agenda. A systematic process should ensure proper application and outcome evaluation of those policies. P2 stated, "Those policies should be made mandatory and there should be a penalty or fine for not following the policy or agenda." T5 explained that "civic education promotes intercultural education but students do not always take it seriously. Other subjects like science and maths have more importance to them." The findings revealed that evidences for best practices in implementing intercultural education should be assessed through national standards and made public to promote these best practices.

\section{National Identity Formation}

Another recursive idea interpreted from the data was education for "identity formation." The participants reiterated the thought that intercultural education in Malaysia should be directed towards formation of singular identity among different races. T4 stressed that "students shouldn't be labeled or identified as Chinese, Indian, Malay, or Sarawakian...these identity labels get into their hearts and mind and they don't understand what it is like to be a Malaysian." The discourse towards this agenda also revealed inconsistencies and limitations of the current approaches that highlighted the way forward towards the attainment of this objective using potential strategies. Diversity practitioners articulated this vision by suggesting establishment of an inclusion and equity agenda as the primary policy for intercultural education in Malaysia to overcome the divide and form a uniform identity. DT1 expressed:

The areas that are vulnerable and have potential of creating divide between communities should be monitored through equity and inclusion policies. Schools, curriculum, teaching and other elements in school support structure should be evaluated to ensure they promote inclusion.... The equity in terms of fulfilling needs of all students will have them see each other as same.

It was revealed that the challenges in forming a uniform identity as "Malaysian" become critical when children get to attend vernacular schools that impart education using the native language of the students. For example, a Tamil vernacular school would use Tamil as the medium of instruction. As P3 described, 
"One school for all can help student forget about their race tag. In such places (vernacular schools) students are constantly reminded of their racial identity." However, for intercultural education to shape a uniform identity for Malaysian students, the participants suggested that "drastic" modification be made in education and in the overall structure of national school. For instance, P1 stated, "We remember going to national schools that were race blind.... Now if national schools display uniform and neutral policies and practices they can attract students from all races." Principal participants emphasized that understanding and internalizing the concept and philosophy of nation building and nurturing values for patriotism through intercultural education was perceived as one of the critical elements in developing uniform identity in a multiracial society. L2 expressed:

Identity crisis is damaging Malaysia society seriously; it is a reality that everyone must accept. A well-planned focus on history, moral education, civic subjects...improvement in RIMUP (Race Integrity program) and bringing deep understanding of Rukun Negara (National principle) can develop students to become true Malaysian identity.

Another principal (L1) expressed that "our education not only focuses on cultural awareness but love for the country. All races must immerse in one culture," adding, "Some students cannot sing 'Negara ku' (national anthem) well; they don't take pride in the country and identification as Malaysia." Similarly, promoting Malay language as lingua franca was perceived as the common factor that can bind students and promote Malaysian Identity. T2 remarked that "the use of English as a medium of instruction is justified for creating global competence but the promotion of Bahasa Malay (Malay language) is essential to create love and connectedness for the nation."

\section{Establishing Diversity Climate}

The data suggest that elements of interculturalism are intertwined and their interaction in a positive way should create an environment of trust and optimism to facilitate social cohesion. According to the participants, the nature of elements varies from teachers, leaders, parents, and community to dialogue, documents, policies, and practices that can influence the environment. A student (HS2) remarked, "Teachers are the role models and they must be most careful and not do discriminatory practices at school that can be seen by students...." The idea continues with a parent (P2) saying, "Teachers and school leaders are the first contact for students in schools. If they ensure right behavior... a teacher praising a culture of another race... a bond of trust can be formed".

To build mutual trust between partners using an intercultural framework is not enough; rather, partnership and engagement with parents and local community members in the school program can facilitate development of meaningful and trustworthy relationships. T1 suggested "involving community organization and parents at school level to present a model of good practices and collaboration to 
students so they will learn to follow the same." The findings reveal that creating the right climate for diversity to flourish also involves open dialogue and communication among its members. The structured interaction between members can create awareness, stimulate ideas, and increase unity. S4 said, "High school students are capable of discussing such issues in proper manner; the education structure should promote such discussion." Schools have the privilege to promote intercultural dialogue and offer a platform to its stakeholders to discuss issues surrounding cultural coexistence. P2 added that "we hide issues behind a smile. Instead we should have a platform to discuss and talk to clarify misunderstandings." Setting up a stage for intercultural dialogue will promote awareness about each other's cultural. DT2 said, "The dialogue-related activities among students and parents can be introduced in form of a small research and inquiry based project." HS1 noted, "I bond with my friends from different religions the best during festivals or fun events." Moreover, the data suggest a range of activity between different races, such as setting up sports clubs, making house visits, dressing up in different culture costumes and cooking for other cultures, celebrating festivals together, and solving community problems together, which can help enrich the diversity climate and promote social cohesion.

\section{Discussion and Conclusion}

The Malaysian context for intercultural education is guided by the need for social cohesion and national unity among the races that already exist within the system (Yaacob, 2011). Intercultural education design in the Malaysian context requires serious consideration for inclusion and equity for its multiple constituents. The present study utilized data collected from school leaders, school teachers, higher education scholars, diversity trainers, parents, and students using face-toface in-depth interviews with open-ended questions. The findings were summarized into four themes that reflected a broad framework and strategies that can guide a design for intercultural education in Malaysian context.

The first theme suggested diversity awareness among the stakeholders as an essential premise for intercultural education. Multicultural awareness can be conveyed through a variety of sources (e.g., trainings, courses, media, advertisements) for various members in the society through explicit and tacit knowledge using strategies such as case studies, self-evaluations, experiential learning, and intercultural communication that highlight the benefits of heterogeneity for a variety of contexts. Such awareness drives would develop the necessary skills and attitudes for understanding and valuing diversity along with the ability to empathize with others, promote global mindedness, and broaden the worldview (Avery \& Thomas, 2004; Loden, 1996). These, in turn, would lead members to feel valued and appreciated, consequently reducing racial tension within the community (Hurtado, 1992).

The participants also shared concerns on formulation, implementation, and monitoring of policies at school level that are aimed at promoting social cohesion. 
Primarily, the policies should follow ground-up approaches and tools so that they can resonate with the voices of members in the society on the issues and opportunities. Sidney (2002) describes policy formulation not as a stage but as a process where dominant actors come together to decide the course of action. Citizen engagement within policy formulations highlights citizens' democratic rights and duties and the process also ensures justice and equality in the decisionmaking process (Holmes, 2011). The determination of national indicators for evaluation of social cohesion policies can facilitate monitoring and evaluation that would further assist in the revision of standards and criteria for intercultural education (Fuller, 2011).

Other profound evidence from the findings suggests that intercultural education in Malaysian context should promote uniform national identity formation by eliminating hyphenated tags of multiple identities, for example, ChineseMalaysian, or Indian-Malaysian. Education for promoting patriotism to build national identities among students was offered as one of the devices. Kelman (1997) describes patriotism as a set of attitudes and beliefs that refers to individuals' attachment and loyalty to their nation and country (p. 166). Educational approaches that promote appreciation of national artifacts, symbols, language, and other associative identities would unite different people of a nation. Similarly, establishing Malay as lingua franca was rooted in the philosophy of sociocultural perspective and linguistics that common language forms similar cultural patterns of thinking (Kaplan 1966) and would eventually create similar social identities for national unity, as diverse people will have a common medium with which to connect (Windisch, 2004; Hashim, 2009). However, when the population is heterogeneous, minority rights provisions should be taken into account seriously and prevent discriminatory practices in approaches towards uniform identity formation (e.g. UDHR, 1948).

To further streamline this idea, equitable and inclusive practices were among the suggested approaches to be incorporated in intercultural education for social cohesion. Environments that offer equal opportunity and demonstrate inclusion promote feelings of sameness, self-worth, and dignity, which fosters positive attitudes towards civic engagement among members (Osterman, 2000). Finally, the study highlighted the interplay of several factors that can work together to create a diversity climate. According to these findings, teachers' and school leaders' roles were perceived as central to intercultural education. Their multicultural attitudes, beliefs, knowledge, and skills will significantly affect their behaviors such as their instructional approaches, choice of teaching material, and conflict solving strategies (Banks, 1989; Cockrell, Placier, Cockrell, \& Middleton, 1999; Milner, Flowers, Moore, Moore, \& Flowers, 2003). Therefore, diversity training and inclusion of intercultural teaching must be an essential component of teacher education, a component that is evidently absent in Malaysia (Ahmad, Abidin, Jelas, \& Saleha 2011). Another key component identified to establish diversity climate was to create a connection with civil societies and communities by facilitating open dialogue and communication on race issues in educational settings. Such practices would build an atmosphere of trust, sharing, and 
compassion among members, a prerequisite for the idea of unity (AllemannGhionda, 2008).

It is a multidimensional endeavor to accomplish a national agenda for social cohesion. However, the role of schools and intercultural education is seen as an effective medium to achieve these goals. Intercultural education that may vary from one context to another ought to be adapted within local settings. Malaysia is striving for social cohesion through various modes, and education is one of them.

Using insights from the above findings, schools and surrounding communities can devise strategies and approaches that would contribute positively towards this agenda. For example, to bring awareness of valuing and appreciating diversity, schools can encourage inquiry into nations and economies that have flourished as a result of diversity. Such inquiries can be made possible through forums, dialogues, international student exchange programs, research, and problem-solving activities that require multiple perspectives. Similarly, schools can promote classroom dialogue and co-curricular events that are centered on nurturing national identity. One of the approaches could be to have students collectively identify national issues and formulate a framework to solve those issues. Such practices would offer an opportunity for diverse students to collaborate and work together towards shared goals. Other school-based interventions, such as community projects or cultural celebrations that involve understanding cuisine, costumes, artifacts, customs, art, literature, and histories of different cultures, would facilitate the enhancement of a framework for intercultural education.

The present study was an attempt to investigate how Malaysia can strategize intercultural education in its local context. We believe that utilization of a more comprehensive methodology and a more diverse selection of participants would have benefited the outcomes of this study. Nevertheless, the findings offer important insights for educators, researchers, and policy makers to evaluate the present practices and design future programs to achieve social cohesion through intercultural education.

\section{References}

American Educational Research Association. (2016). AERA Statement on the Charleston Shootings and Racism in America. Washington, DC. Retrieved from http://www.aera.net/Newsroom/NewsReleasesandStatements/AERA StatementontheCharlestonShootingsandRacisminAmerica/tabid/16005/De fault.aspx

Ahmad, A. R., Abidin, N. A., Jelas, Z. M., \& Saleha, A. (2011). Teachers' perspectives towards schools diversity in Malaysia. International Journal of Business and Social Science, 2(4), 178-189.

Allemann-Ghionda, C. (2008). Intercultural education in schools: A comparative study. Brussels, Belgium: European Parliament. 
Awang-Hashim, R., Kaur, A., \& Noman, M. (2015). The interplay of sociopsychological factors on school engagement among early adolescents. Journal of Adolescence, 45, 214-224.

Avery, D. R., \& Thomas, K. M. (2004). Blending content and contact: The roles of diversity curriculum and campus heterogeneity in fostering diversity management competency. Academy of Management Learning and Education, 3, 380-396.

Banks, J. A. (1989). Approaches to multicultural curriculum reform, Trotter Review, $3(3), 17-19$.

Bronfenbrenner, U. (1979). The ecology of human development: Experiments by nature and design. Cambridge, MA: Harvard University Press.

Catarci, M. (2014). Intercultural education in the European context: Key remarks from a comparative study, Intercultural Education, 25(2), 95-104.

Chenail, R. J. (2012). Conducting qualitative data analysis: Reading line-by-line, but analyzing by meaningful qualitative units. The Qualitative Report, 17(1), 266-269. Retrieved from http://nsuworks.nova.edu/tqr/vol17/iss1/12

Cockrell, K. S., Placier, P. L., Cockrell, D. H., \& Middleton, J. N. (1999). Coming to terms with "diversity" and "multiculturalism" in teacher education: Learning about our students, changing our practice. Teaching and Teacher Education, 15, 351-366.

Commission of the European Communities. (2010). Investing in Europe's future: Fifth report on economic, social and territorial cohesion. Luxembourg, LU: Publications Office of the European Union. Retrieved from http://ec.europa.eu/regional_policy/sources/docoffic/official/reports/cohesi on5/pdf/5cr_en.pdf

Creswell, J. W. (2015). Educational research: Planning, conducting, and evaluating quantitative and qualitative research (5th ed.). Boston, MA: Pearson.

Cummins. J. (2015). Intercultural education and academic achievement: A framework for school-based policies in multilingual schools. Intercultural Education, 26(6), 455-468.

Denson, N., \& Chang, M. J. (2009).Racial diversity matters: The impact of diversity-related student engagement and institutional context. American Educational Research Journal, 46(2), 322-353.

De Wit, H. (2011). Trends, issues and challenges in internationalisation of higher education. Amsterdam, Netherlands: Centre for Applied Research on Economics and Management, Hogeschool van Amsterdam

Fakhri, R. K. (2012). The Malaysian experience in developing national identity, multicultural tolerance and understanding through teaching curricula: Lessons learned and possible applications in the Jordanian context. International Journal of Humanities and Social Science, 2(1), 270-288. 
Fisher, M. (2013, May 15). A fascinating map of the world's most and least racially tolerant countries. The world view, The Washington Post. Retrieved from https://www.washingtonpost.com/news/worldviews/wp/2013/05/15/afascinatingmap-of-the-worlds-most-and-least-racially-tolerant-countries/

Fuller, C. (2011). Measuring performance in community cohesion. In P. Ratcliffe \& I. Newman (Eds.), Promoting social cohesion: Implications for policy and evaluation (pp. 61-80). Bristol, United Kingdom: University of Bristol, Policy Press.

Gall, M. D., Gall, J. P., \& Borg, W. R. (2003). Educational research: An introduction (7th ed.). Boston, MA: A \& B Publications.

Ha, P. L., Kho, J., \& Chng, B. (2013). Nation building, English as an international language, medium of instruction, and language debate: Malaysia and possible ways forward. Journal of International and Comparative Education, 2(2), 58-71.

Harvey, L. (2015). Beyond member-checking: A dialogic approach to the research interview. International Journal of Research \& Method in Education, 38, 23 38.

Hashim, A. (2009). Not plain sailing: Malaysia's language choice in policy and education. AlLA Review, 22(1), 36-51.

Holmes, B. (2011). Citizens' engagement in policymaking and the design of public services: Research paper No. 1. Canberra, Australia: Department of Parliamentary Services.

Hurtado, S. (1940). The institutional climate for talented Latino students. Research in Higher Education, 35, 21-41.

Jansen, H. (2010). The logic of qualitative survey research and its position in the field of social research methods [63 paragraphs]. Forum Qualitative Sozialforschung [Forum: Qualitative Social Research], 11(2). Retrieved from http://nbn-resolving.de/urn:nbn:de:0114-fqs1002110

Kaplan, R. (1966). Cultural thought patterns in inter-cultural education. Language Learning, 16(2), 11-25.

Kelman H. C. (1997). Nationalism, patriotism, and national identity: Socialpsychological dimensions. In D. Bar-Tal \& E. Staub (Eds.), Patriotism in the life of individuals and nations (pp. 165-189). Chicago, IL: Nelson-Hall.

Loden, M. (1996). Implementing diversity. Chicago, IL: Irwin Publishing.

Malakolunthu, S. (2009). Educational reform and policy dynamics: A case of the Malaysian "Vision School" for racial integration. Educational Research for Policy and Practice, 8(2), 123-134.

Malakolunthu, S., \& Rengasamy, N.C. (2013). Education policies and practices to address cultural diversity in Malaysia: Issues and challenges. Prospects, 42(2), 147-159. 
Malakolunthu, S., Saedah S., \& Rengasamy, N. C. (2010). Multicultural education as a reform initiative: Reconstructing teacher preparation for Malaysian "Vision Schools." The Asia-Pacific Education Researcher, 19(3), 453-464.

Milner. H. R., Flowers, L. A., Moore, E., Moore, J. L., \& Flowers, T. A. (2003). Preservice teachers' awareness of multiculturalism and diversity. The High School Journal, 32(1), 63-70.

Montesino, M. U. (2011). Cross-cultural conflict and affirmative action: inter- and intra-ethnic dilemmas of Malaysia's heterogeneous workplace. International Journal of Cross Cultural Management, 12(1), 115-132.

Osterman, K. (2000). Students' need for belonging in the school community. Review of Educational Research, 70(3), 323-367.

Rutkowski, D., Rutkowski, L., \& Engel, L. C. (2014). Inclusive schooling: Fostering citizenship among immigrant students in Europe. Intercultural Education, 25(4), 269-282.

Saad, S. (2012). Re-building the concept of nation building in Malaysia. Asian Social Science, 8(4), 115-123.

Schaefer, D. R., \& Dillman, D. A. (1998). Development of a standard e-mail methodology: Results of an experiment. Public Opinion Quarterly, 62, 378397.

Shahran, M. F. M. (2014, April 9). Differences can be blessings. The Star Online. Retrieved from http://www.thestar.com.my/opinion/columnists/ikim-views/ 2014/04/29/differences-can-be-blessings/

Sidney, M. S. (2007). Policy formulation: Design and tools. In F. Fischer, G. J. Miller, \& M. S. Sidney (Eds.), Handbook of public policy analysis: Theory, politics and methods (pp. 79-87). New Brunswick, NJ: CRC Taylor \& Francis.

Tajfel, H., \& Turner, J. (1979). An integrative theory of intergroup conflict. In W. G. Austin \& S. Worchel (Eds.), The social psychology of intergroup relations (pp. 33-48). Monterey, CA: Brooks/Cole.

Terenzini, P. T., Cabrera, A. F., Colbeck, C. L., Bjorklund, S. A., \& Parente, J. M. (2001). "Racial and ethnic diversity in the classroom: Does it promote student learning?" The Journal of Higher Education, 72(5), 509-529.

United Nations. (2013). Number of international migrants rises above 232 million. Retrieved from http://www.un.org/apps/news/story.asp?NewsID=45819\#. WRAMNTKGOM8

UDHR. (1948). Universal declaration of human rights, United Nations General Assembly. Retrieved from http://www.un.org/apps/news/story.asp?NewsID $=45819$

Van Knippenberg, D., West, M. A., Dawson, J. F., \& Homan, A. C. (2010). Diversity faultlines, shared objectives, and top management team performance. Human Relations, 64, 307-336. 
Vergolini, L. ( 2011). Social cohesion in Europe: How do the different dimensions of inequality affect social cohesion? International Journal of Comparative Sociology 52(3), 197-214.

Windisch, U. (2004). Beyond multiculturalism: Identity, intercultural communication and political culture - the case of Switzerland. In D. Judd \& T. Lacorne (Eds.), Language, nation and state: Identity politics in a multilingual age (pp. 161-184). Basingstoke, United Kingdom: Palgrave Macmillan.

Yaacob, M. F. (2011). The challenge of religious pluralism in Malaysia, The Journal of Oriental Studies, 21, 166-177.

Yusof, N. M. (2008). Multicultural education: Managing diversity in Malaysian schools. Malaysian Education Deans Council Journal, 2. Retrieved from http://web.usm.my/education/publication/10\%20najeemah\%28149-165\% 29.pdf

\section{Author Contact}

Amrita Kaur: amrita@uum.edu.my

School of Education and Modern Languages, College of Arts and Sciences, Universiti Utara Malaysia, Sintok, Kedah, Malaysia. 06010

Rosna Awang-Hashim: rosna@uum.edu.my

School of Education and Modern Languages, College of Arts and Sciences, Universiti Utara Malaysia, Sintok, Kedah, Malaysia. 06010

Mohammad Noman: mdnoman@yahoo.com

School of Education and Modern Languages, College of Arts and Sciences, Universiti Utara Malaysia, Sintok, Kedah, Malaysia. 06010 